\title{
Occurrence of Delirium and Length of Stay of Patients in the Intensive Care Unit
}

\author{
Aparecida Sátira da Silva Machado, Mayara Rabello Teixeira Alves, Daniella Nogueira Vieira, \\ Sara Ellias de Sousa, Felipe Rodrigues Maia, Daniel Almeida da Costa, Leandro Raider
}

The Medical School at the Center of Higher Education of Valença, Unifaa, Brazil

Email: daniel.almeida@faa.edu.br

How to cite this paper: da Silva Machado, A.S., Alves, M.R.T., Vieira, D.N., de Sousa, S.E., Maia, F.R., da Costa, D.A. and Raider, L. (2021) Occurrence of Delirium and Length of Stay of Patients in the Intensive Care Unit. Journal of Biosciences and Medicines, 9, 1-9.

https://doi.org/10.4236/jbm.2021.98001

Received: June 26, 2021

Accepted: July 31, 2021

Published: August 3, 2021

Copyright $\odot 2021$ by author(s) and Scientific Research Publishing Inc. This work is licensed under the Creative Commons Attribution International License (CC BY 4.0).

http://creativecommons.org/licenses/by/4.0/

(c) (i) Open Access

\begin{abstract}
Introduction: The delirium has received little attention from professionals working in the intensive care unit, mainly due to the fact that this is, rarely, the primary reason for patient admission. Given the high prevalence of delirium in an intensive care environment, the current guidelines recommend the daily assessment of delirium and a multidisciplinary approach. Delirium is a frequent and severe form of acute brain dysfunction, as well as an important source of concern in critical care. Objective: To assess the occurrence of delirium and time of stay in the intensive care unit. Method: This is a quantitative, descriptive study, with a cross-sectional design, which was carried out in a university hospital located in the interior of the State of Rio de Janeiro. The sample consisted of 89 patients, of both sexes, aged between 24 and 92 years. The RASS and CAM-ICU scales were used to assess delirium. The data were collected every 12 hours, for 3 months, 7 days a week and in an uninterrupted manner. Results: Were evaluated 89 patients, of which 16 were excluded according to the scale criteria, leaving 73 patients. After evaluation, 22 patients were diagnosed with delirium and 51 patients without delirium. Of the patients who presented delirium, 13 deaths and 9 had high to the nursery. Of the patients who did not have delirium, 40 had high to the nursery and 11 deaths. Patients with delirium had an average hospital stay of 23.25 days and patients who did not have delirium had an average of 4.5 days hospitalization. Conclusion: We can infer that the longer the patient spends in the intensive care unit, the greater the chance of delirium occurring. Therefore, preventive and interventional measures are necessary to decrease the mortality rate in patients with delirium and early detection is an excellent tool to improve this outcome.
\end{abstract}

\section{Keywords}

Delirium, Intensive Care Unit, Time of Hospitalization 


\section{Introduction}

Delirium can be defined as an acute brain dysfunction characterized by transient and fluctuating changes in the state of consciousness, accompanied by cognitive impairment, which frequently affects patients admitted to intensive care units (ICU) [1]. It occurs in a short period (hours or days), is generally reversible and can be a direct consequence of a medical condition, intoxication or withdrawal syndrome, caused by the use of drugs even in therapeutic concentration, exposure to toxins or a combination of these factors [2]. Environmental factors can also trigger it, such as stress induced by ignorance of the environment, alarm noise, constant changes in professionals who provide assistance and care or procedures poorly explained to patients [2].

Currently, the most accepted theory of the pathophysiology of delirium is that the decrease in cholinergic activity associated with dopaminergic increase, corroborated by the lack of attention caused by anticholinergic medications, causes such symptoms. From a neuroscience perspective, it is believed that delirium is related to an imbalance in the synthesis, release and inactivation of neurotransmitters, modulating the control of cognitive function, behavior and mood [3].

Delirium is a syndrome that can occur as a result of multiple and complex interactions between neurotransmitter systems and pathological processes. The neurotransmitters, acetylcholine and serotonin, may play an important role in delirium due to common clinical conditions, as well as in post-surgical delirium. Other neurotransmitters dopamine and GABA and neurobiological factors such as cytokines, hormones and free radicals will need further study to define their participation in the genesis of delirium. Future studies focused on the pathophysiology of delirium may lead to better prevention and treatment strategies [3].

The prevalence of delirium in critically ill patients varies between different studies and can affect approximately $80 \%$ of patients admitted to the Intensive Care Unit, using mechanical ventilation, however, only $32 \%$ to $66 \%$ of patients are correctly diagnosed and treated [2]. Delirium remains considerably underdiagnosed despite its high prevalence in the intensive care unit (ICU). There are reports of ICU prevalence ranging from $28 \%$ to $73 \%$. This variation can be attributed to the heterogeneity of the population assessed (for example, disease severity, patients on mechanical ventilation or not, elderly) as well as the definition of delirium and the instrument chosen for its detection [4].

Delirium has received little attention from professionals working in the ICU, mainly due to the fact that this is rarely the primary reason for admission of patients [2]. Given the high prevalence of delirium in the intensive care setting, current guidelines recommend daily assessment of delirium and a multidisciplinary approach [1]. Delirium is a frequent and severe form of acute brain dysfunction and an important source of concern in critical care. In the last ten years, studies have clearly demonstrated an association between delirium and increased mortality, duration of mechanical ventilation and hospital stay [5].

Considered a geriatric emergency, delirium is associated with a worse progno- 
sis for the patient, as it increases in-hospital mortality (mortality in hospitalized patients with delirium ranges between $22 \%$ and $76 \%$ ), length of stay and the risk of medical complications; favors the decline of functional capacity and the development of dementia; increases the risk of institutionalization [6].

In critically ill patients, the most used diagnostic scales, due to their simplicity and adequate accuracy, are the Confusion Assessment Method for the Intensive Care Unit (CAM-ICU) and the Intensive Care Delirium Screening Checklist (ICDSC) [7]. The CAM-ICU was created, based on the DSM-IV criteria (DSM-IV refers to a clinically significant behavioral or psychological syndrome or pattern that occurs in an individual), with the objective of facilitating the diagnosis of delirium in the ICU and allowing the evaluation of patients on mechanical ventilation (incapable of verbal communication) [7].

Delirium is a critical and highly prevalent problem among critically ill patients. The Intensive Care Unit Confusion Assessment Method (CAM-ICU) and the Intensive Care Delirium Screening Checklist (ICDSC) are the most recommended assessment tools for detecting delirium in the intensive care unit (ICU) [8]. CAM-ICU has high sensitivity, is widely studied and suggested as a tool of choice for the diagnosis of delirium [9]. For the mixed ICU population, CAM-ICU remained more sensitive than ICDSC [10].

Currently, tools are available for diagnosing critical patients, even if they are on mechanical ventilation. However, it is necessary to organize a systematized and standardized routine that enables the use of these tools. As delirium is often forgotten in clinical routine, ongoing screening for delirium should be performed [11].

The validated instruments allow the diagnosis and monitoring of delirium, enabling the early start of treatment. The low incidences of delirium and the implementation of preventive measures should be a frequent objective for quality improvement in the ICU, and may represent a better process of care and optimization of patient-centered outcomes [4]. Delusional patients who remained in the ICU for a long period presented greater need for ventilatory support and higher mortality in the ICU [12].

Teaching and interprofessional involvements are essential for the successful implementation of delirium assessment practice in the intensive care unit. Improving nurses' knowledge can lead to better delirium management practice and improve patient care in the ICU. The practice of teaching and the involvement of the care team is essential for a successful implementation of delirium assessment in the ICU [13]. It is for all the impact it has on health services, professionals and, above all, on patients and their families, that we suggest paying more attention to delirium and, why not, considering it as the 7th vital sign [14].

Therefore, we consider it important to develop research that provides knowledge of this syndrome and the scenario to be investigated, in order to contribute to the implementation of a systematized and standardized routine for the diagnosis of delirium, enabling an early multidisciplinary care with interventional 
and preventive measures to the treatment of delirium.

The aim of this study is to assess the occurrence of delirium and the length of stay of patients in the Intensive Care Unit.

\section{Methods}

This is a quantitative, descriptive study with a cross-sectional design, which was carried out at a university hospital located in the interior of the State of Rio de Janeiro. The sample consisted of 89 patients, of both genders, aged between 24 and 92 years, who have passed through the intensive care unit. So these patients, were framed in the following criteria: To assess delirium, the RASS (Richmond Agitation Sedation Scale) and CAM-ICU scales were used. Data were collected every 12 hours, for 3 months, 7 days a week and without interruption.

To make the diagnosis of delirium, it was necessary to combine sedation and delirium monitoring, using the two-step method for assessing consciousness. The first step refers to the assessment of sedation and agitation, quantified by the Richimond Scale of Agitation-RASS Sedation, which has already been implemented in the service. The rating scale ranges from +4 to -5 .

The attribution of scores to the patient by the RASS scale was done as follows: score zero refers to the alert patient, without apparent agitation or sedation. Levels below zero mean some degree of sedation, levels above zero mean that the patient has some degree of agitation.

The procedure for analyzing the RASS Scale is as follows: 1) Observe the patient. If he is alert, restless or agitated: 0 to +4 . 2) If he is not alert, say the patient's name and ask him to open his eyes and look at the professional. If awake, with sustained eye opening and making eye contact: -1 . If awake, perform eye opening and brief eye contact: -2 . If able to make some kind of movement, but without eye contact: -3 . 3) When the patient does not respond to verbal stimulus, perform physical stimuli. If he performs any movement to the physical stimulus: -4 . If it does not respond to any stimulus: -5 .

After patient assessment, according to the RASS definition, all patients whose classification was greater than -4 and less than +4 , proceeded to the second step. That is, those classified as RASS -4 and -5 were excluded due to intense sedation, as well as those classified as RASS +4 due to intense agitation.

After determining the RASS, the second step was continued, this being the assessment using the Confusional Assessment Method in Intensive Care Unit (CAM-ICU) scale, which allowed for the identification of delirium episodes in critically ill patients.

According to the Diagnostic and Statistical Manual of Mental Disorders-5 (DSM-5), delirium is defined as: 1) Altered consciousness with decreased ability to maintain, alter or focus attention; 2) Change in cognition (memory, orientation, language) or the development of change in perception that cannot be explained by an established, pre-existing or evolving dementia condition; 3) The changes described develop in a short period of time, usually hours to days, and 
tend to fluctuate throughout the day 14.

In Brazil, the CAM scale has been validated and its use has been increasing as a diagnostic support for delirium. In order to address this critical care population, researchers at Vander Bilt Medical Center, in Nashville, developed an adapted version of the CAM, called: Confusion Assessment Method for Intensive Care Units (CAM-ICU) and contains four criteria: 1) acute change of baseline or fluctuating course; 2) inattention; 3) disorganized thinking and 4) altered level of consciousness (Figure 1). An altered level of consciousness should be understood as any behavior that does not alert you, such as waking, lethargic or torporous. Thus, for the diagnosis of Delirium, the presence of characteristics 1 and 2 plus the presence of characteristics 3 or $4,1+2+3$ or $1+2+4$ is necessary.

This study was approved by the research ethics committee of the centro universitário de valença under the number CAAE 66401617.3.0000.5246.

\section{Results}

The first phase comprised 89 patients admitted to the Intensive Care Unit, who underwent the RASS scale, following the exclusion criteria. Thus, 16 patients were excluded, as they fit into classification -4 , deeply sedated or -5 , patient in a coma, unresponsive to verbal stimuli or physical examination, representing $18 \%$ of the sample.

Table 1 shows the distribution of these patients in the period, where $82 \%$ were included in the sample, which means that 73 patients went to the second phase, for evaluation using the CAM-ICU scale for diagnosis and monitoring of delirium.

In Table 2, with the execution of the second step in those patients eligible for the RASS scale, we see that the prevalence of delirium was $30 \%$, that is, of 73 patients evaluated in the period, 22 were diagnosed with delirium at some point during the period of stay in the ICU, following the diagnostic criteria of the CAM-ICU scale.

Regarding the length of stay in the ICU, we performed two analyses: the first, comparing the length of stay between those who had and did not have delirium,

\begin{tabular}{|c|l|l|}
\hline \multicolumn{2}{|l}{ Richmond Agitation Sedation Scale - RASS } \\
\hline 4 & Combative & Violent, immediate danger to staff \\
\hline 3 & Very agitated & Pulls or removes tube (s) or catheter (s); agressive \\
\hline 2 & Agitated & Frequent non-purposeful movements; fights ventilator \\
\hline 1 & Restless & Anxious, apprehensive but movements not aggressive, or vigorous \\
\hline 0 & Alert \& calm & \\
\hline-1 & Drowsy & Not fully alert, but has sustained awakening to voice (eye opening \& contact $\geq 10$ sec) \\
\hline-2 & Light Sedation & Briefly awakens to voice (eye opening \& contact $<10$ sec) \\
\hline-3 & Moderate Sedation & Movement or eye-opening to voice (but not eye contact) \\
\hline-4 & Deep Sedation & No response to voice, but movement or eye opening to physical stimulation \\
\hline-5 & Unarousable & No response to voice or physical stimulation \\
\hline
\end{tabular}

Figure 1. Richmond agitation and sedation scale. 
Table 1. Distribution of patients assessed by the RASS scale in the ICU.

\begin{tabular}{ccc}
\hline & Sample & $\%$ \\
\hline Excluded by RASS & 16 & 17.98 \\
Assessed by CAM-ICU & 73 & 82.02 \\
Total patients & 89 & 100.00 \\
\hline
\end{tabular}

Table 2. Distribution of patients evaluated by CAM-ICU in the ICU.

\begin{tabular}{ccc}
\hline & Sample & $\%$ \\
\hline With delirium & 22 & 30.14 \\
Without delirium & 51 & 69.86 \\
Total of patients & 73 & 100.00 \\
\hline
\end{tabular}

Table 3. Length of hospital stay in patients with and without delirium.

\begin{tabular}{ccc}
\hline & Average & Median \\
\hline With delirium & 23.25 & 10.5 \\
Without delirium & 4.5 & 3.5 \\
\hline
\end{tabular}

Table 4. Mean and median days of hospitalization for patients with delirium.

\begin{tabular}{ccc}
\hline & Average & Median \\
\hline Death & 32.61 & 17 \\
Discharge to the ward & 6 & 7 \\
\hline
\end{tabular}

and the second, comparing the time to discharge/death outcome in those who had delirium.

In Table 3, we see that patients with delirium had a mean hospital stay of 23.25 days and a median of 10.5 days, and those who did not have delirium had an average of 4.5 days and a median of 3.5 days.

Table 4 shows the relationship between length of stay and the outcome of patients who had delirium, and those who were discharged to the ward had an average of 6 days of hospitalization and a median of 7, whereas those who had been delirium and who progressed to death had an average of 32.61 days of hospitalization and a median of 17 days.

Regarding the outcome of the 22 patients with delirium, Table 5 shows that $59.09 \%$ (13) evolved to death and $40.91 \%$ (9) were discharged to the ward.

Use Assessing the outcome of patients without delirium, Table 6 shows that $78.43 \%$ (40) were discharged to the ward, while 11 evolved to death, representing $21.57 \%$ of the sample.

The risk factors of the delirium among the patients and the cause of the death, were not described in this study, as the aim of the study was to assess the occurrence of delirium and time of stay in the intensive care unit. 
Table 5. Outcome of patients with delirium in the ICU.

\begin{tabular}{ccc}
\hline & Sample & $\%$ \\
\hline Death & 13 & 59.09 \\
Discharge to the ward & 9 & 40.91 \\
Total of patients & 22 & 100.00 \\
\hline
\end{tabular}

Table 6. Outcome of patients without delirium in the ICU.

\begin{tabular}{ccc}
\hline & Sample & $\%$ \\
\hline Death & 11 & 21.57 \\
Discharge to the ward & 40 & 78.43 \\
Total of patients & 51 & 100.00 \\
\hline
\end{tabular}

\section{Discussion}

Delirium is the most common form of acute brain dysfunction in ICU and affects up to $80 \%$ of patients, however, it is often undervalued and not recognized in the same way as other organ dysfunction 1 . There are reports of ICU prevalence ranging from $28 \%$ to $73 \%$. This variation can be attributed to the heterogeneity of the population assessed (for example, disease severity, patients on mechanical ventilation or not, elderly) as well as the definition of delirium and the instrument chosen for its detection [4].

The CAM-ICU scale, unprecedented in use in this ICU, proved to be a simple, fast and easy to apply scale. It only required a quick training which allowed its proper use. The analyzes show a $30 \%$ prevalence of delirium in the population studied, and this result is compatible with previous studies, which show a variation of $28 \%$ to $80 \%$ in critically ill patients in the ICU, which may be even greater in those under invasive mechanical ventilation.

Even so, we must consider here the fluctuating characteristic of delirium, and this value may be underestimated, since the evaluations were made only twice a day. We believe that if CAM-ICU is implemented in the service and used systematically, by all professionals who assist those patients, within 24 hours, a greater number of cases will be diagnosed. It is important to monitor delirium because it is often underdiagnosed (3\% - 66\% of cases of Delirium in the intensive care unit are undiagnosed) and has important prognostic implications for the patient [1].

When comparing the total public and the public with delirium with the length of stay in the sector, we observed that this time was up to 5 times longer than those who did not have delirium. Thus, we believe that delirium is related to an increase in the length of hospital stay and death, thus presenting itself as a predictor of poor prognosis.

Among the patients who had delirium, 13 progressed to death, that is, a rate of $59 \%$. When compared with the $22 \%$ mortality rate among those who did not 
have delirium, we observed that, in this study, patients with delirium had a 2.7 times greater chance of progressing to death, which corroborates the concept of previous studies that delirium is associated with a worse prognosis and increased mortality. According to the study developed by Pessoa [2], its development was associated with a three-fold increase in the risk of death, after controlling for preexisting comorbidities, disease severity and the use of sedative and analgesic medications. More studies are needed to confirm these criteria for the relationship between delirium and length of hospital stay and risk of death.

\section{Conclusion}

We can infer that the longer the patient spends in the intensive care unit, the greater the chance of delirium. Therefore, preventive and interventional measures are needed to reduce the mortality rate in patients with delirium, and early detection is an excellent tool to improve this outcome.

\section{Conflicts of Interest}

The authors declare no conflicts of interest regarding the publication of this paper.

\section{References}

[1] Faria, R. da S.B. and Moreno, R.P. (2013) Delirium na unidade de cuidados intensivos: Uma realidade subdiagnosticada. Revista Brasileira de Terapia Intensiva, 25, 137-147.

[2] Pessoa, R.F. and Nácul, F.E. (2006) Delirium em Pacientes Críticos. Revista Brasileira de Terapia Intensiva, 18, 190-195. https://doi.org/10.1590/S0103-507X2006000200013

[3] Bastos, A.S., Beccaria, L.M., Silva, D.C. and Barbosa, T.P. (2020) Prevalência de delirium em pacientes de terapia intensiva e associação com sedoanalgesia, gravidade e mortalidade. Revista Gaúcha de Enfermagem, 41, e20190068. https://doi.org/10.1590/1983-1447.2020.20190068

[4] Pitrowsky, M.T., Shinotsuka, C.R., Soares, M., Lima, M.A.S.D. and Salluh, J.I.F. (2010) Importância da monitorização do delirium na unidade de terapia intensiva. Revista Brasileira Terapia Intensiva, 22, 274-279. https://doi.org/10.1590/S0103-507X2010000300010

[5] Shinotsuka, C.R. and Salluh, J.I.F. (2013) Percepções e práticas sobre delirium, sedação e analgesia em pacientes críticos: Uma revisão narrativa. Revista Brasileira de Terapia Intensiva, 25, 155-161. https://doi.org/10.5935/0103-507X.20130027

[6] Ito, C.M. and Pedri, L.E. (2017) O uso da terapia farmacológica para a profilaxia do delirium: Revisão sistemática. Revista Brasileira de Clínica Médica, 11, 1-5.

[7] Carvalho, J.P.L.M., Almeida, A.R.P. and Gusmão-Flores, D. (2013) Escalas de avaliação de delirium em pacientes graves: Revisão sistemática da literatura. Revista Brasileira Terapia Intensiva, 25, 148-154. https://doi.org/10.5935/0103-507X.20130026

[8] Boettger, S., Nunes Meyer, R., Ritcher, A., Fernandez, S.F., Rudiger, A., Schubert, M. and Jenewein, J. (2017) Delirium in the Intensive Care Setting: A Reevaluation of the Validity of the CAM-ICU and ICDSC versus the DSM-IV-TR in Determining a 
Diagnosis of Delirium as Part of the Daily Clinical Routine. Palliative \& Supportive Care, 15, 675-683. https://doi.org/10.1017/S1478951516001176

[9] Kuczmarska, A., Ngo, L.H., Guess, J., O’connor, M.A., Branford-White, L., Palihnich, K., Gallagher, J. and Marcantonio, E.R. (2016) Detection of Delirium in Hospitalized Older General Medicine Patients: A Comparison of the 3D-CAM and CAM-ICU. Journal of General Internal Medicine, 31, 297-303. https://doi.org/10.1007/s11606-015-3514-0

[10] Barman, A., Pradhan, D., Bhattacharyya, P., Dey, S., Bhattacharjee, A., Tesia, S.S. and Mitra, J.K. (2018) Diagnostic Accuracy of Delirium Assessment Methods in Critical Care Patients. Journal of Critical Care, 44, 82-86. https://doi.org/10.1016/j.jcrc.2017.10.013

[11] Zoremba, N., Coburn, M. and Schälte, G. (2018) Delirium in Intensive Care Patients: A Multiprofessional Challenge. Der Anaesthesist, 67, 811-820.

https://doi.org/10.1007/s00101-018-0497-3

[12] Kanova, M., Sklienka, P., Roman, K., Burda, M. and Janoutova, J. (2017) Incidence and Risk Factors for Delirium Development in ICU Patients-A Prospective Observational Study. Biomed Pap Med Fac Univ Palacky Olomouc Czech Repub, 161, 187-196. https://doi.org/10.5507/bp.2017.004

[13] Ramoo, V., Abu, H., Rai, V., Surat Singh, S.K., Baharudin, A.A., Danaee, M. and Thinagaran, R.R.R. (2018) Educational Intervention on Delirium Assessment Using Confusion Assessment Method-ICU (CAM-ICU) in a General Intensive Care Unit. Journal of Clinical Nursing, 27, 4028-4039. https://doi.org/10.1111/jocn.14525

[14] Prayce, R., Quaresma, F. and Neto, I.G. (2018) Delirium: The 7th Vital Sign? Acta Médica Portuguesa, 31, 51-58. https://doi.org/10.20344/amp.9670 